\title{
Erratum to: Numerical-Analytical Study of Linked Orbits in the Restricted Elliptic Doubly Averaged Three-Body Problem
}

\author{
M. A. Vashkov'yak* \\ Keldysh Institute of Applied Mathematics, Russian Academy of Sciences, Moscow, 125047 Russia \\ *e-mail:vashkov@keldysh.ru
}

Received June 21, 2021; revised June 21, 2021; accepted June 21, 2021

DOI: $10.1134 / \mathrm{S} 0038094621330029$

The article "Numerical-Analytical Study of Linked Orbits in the Restricted Elliptic Doubly Averaged Three-Body Problem", written by M.A. Vashkov'yak, was originally published electronically in SpringerLink on 8 April 2021 without Open Access. After publication in volume 55, issue 2, pages 159-168 the authors decided to make the article an Open Access publication. Therefore, the copyright of the article has been changed to (C) The Author(s) 2021 and the article is forthwith distributed under the terms of a Creative
Commons Attribution 4.0 International License (http://creativecommons.org/licenses/by/4.0/, CC BY), which permits use, duplication, adaptation, distribution and reproduction of a work in any medium or format, as long as you cite the original author(s) and publication source, provide a link to the Creative Commons license, and indicate if changes were made.

The original article can be found online at https://doi.org/10.1134/S0038094621020064 